\title{
Transperineal ultrasound evaluation of females with stress urinary incontinence
}

\author{
Mohamed S. Sweed ${ }^{1}$, Sherene Sharara ${ }^{2}$
}

\author{
${ }^{1}$ Department of Obstetrics and Gynecology, Ain-Shams University, Cairo, Egypt \\ ${ }^{2}$ Department of Radiodiagnosis, Ain-Shams University, Cairo, Egypt
}

Received: 02 February 2016

Accepted: 10 February 2016

\section{*Correspondence:}

Dr. Mohamed S. Sweed,

E-mail: drmsweed@med.asu.edu.eg

Copyright: () the author(s), publisher and licensee Medip Academy. This is an open-access article distributed under the terms of the Creative Commons Attribution Non-Commercial License, which permits unrestricted non-commercial use, distribution, and reproduction in any medium, provided the original work is properly cited.

\begin{abstract}
Background: Urinary incontinence has a significant influence on the well-being of affected females. No standard imaging modality is mandatory in initial evaluation of patients with urinary incontinence. Transperineal ultrasound has been proposed as a reliable method to assess female stress urinary incontinence. This study was conducted to evaluate the transperineal ultrasound findings in females with stress urinary incontinence.

Methods: A case-control study including 40 females diagnosed to have stress urinary incontinence and 40 healthy females as their controls. The proximal pubo-urethral distance, the posterior urethro-vesical angle $(\beta$-angle) and the angle of urethral inclination ( $\alpha$-angle) were measured at rest and during straining.

Results: On analyzing the transperineal ultrasound findings, no statistical significant difference was found between cases and controls at rest, but on straining, statistical significant difference was found regarding dynamic posterior urethral angle and dynamic pubo-urethral distance ( $p<0.001)$. Of the included 40 cases with SUI, $27(67.5 \%)$ had cysto-urethrocele, and $5(12.5 \%)$ had intrinsic sphincter defect (ISD). Urethral diameter was significantly different in patients with ISD $(6.64 \pm 1.23 \mathrm{~mm})$ when compared with patients with SUI without ISD $(4.83 \pm 1.16 \mathrm{~mm})$.

Conclusions: Transperineal ultrasound is a simple, noninvasive, and easily conducted examination that can be used in the diagnostic workup of stress incontinence.
\end{abstract}

Keywords: Angle of urethral inclination, Intrinsic sphincter deficiency, Posterior urethro-vesical angle, Proximal pubo-urethral distance, Stress urinary incontinence, Transperineal ultrasound

\section{INTRODUCTION}

Urinary incontinence (UI) is a very distressing disease affecting the well-being of patients both physically, psychologically and socially. ${ }^{1}$ Its overall prevalence is approximately $40 \%$ among women. ${ }^{2}$ Stress urinary incontinence (SUI) is the comments type with significant impact on women's quality of life. ${ }^{3}$

The pathological basis of SUI is the absence of proper anatomical support to the proximal urethra, bladder neck and bladder base leading to their hyper-mobility outside the intra-abdominal transmission zone. ${ }^{4}$
Several diagnostic modalities have been proposed, both history and physical examination lack the sufficient sensitivity and specificity for diagnosis of SUI. The standard method for diagnosis and differentiation between different types of SUI is the urodynamic study. This diagnostic tool, however, is not available in all institutes. Moreover, it is quite discomforting to some women. Other imaging modalities as pelvic floor ultrasonography, cysto-urethrography and magnetic resonance imaging (MRI) have been used to evaluate patients with SUI.

Pelvic floor ultrasonography can assess and evaluate pelvic floor muscle (PFM) exercise performance by direct visualization of PFM contraction and movement. ${ }^{6}$ 
Transperineal (TP) ultrasonography seems to be a reliable modality for the assessment of bladder neck mobility and PFM contraction and exercise. ${ }^{7}$ It is an easy, inexpensive technique, and is considered comfortable for most patients. Nowadays, it has become frequently used as a complementary examination in diagnostic investigations. ${ }^{8}$ Yet, this modality still needs further evaluation to reach more standard and objective parameters to be a more efficient diagnostic tool of UI. ${ }^{9}$ This work aims to evaluate the findings of TP ultrasonography in female SUI.

\section{METHODS}

The current case control study was conducted at Ain Shams University Maternity Hospital during the period between February 2014 and January 2015. The study protocol was in agreement to the Helsinki Declaration of Ethical Medical Research, and was approved by the Ethical Medical Research Committee of Radiodiagnosis department, Ain Shams University. All included women signed an informed written consent after thorough explanation of the procedure and purpose of the studies. Forty women with a diagnosis of primary urodynamic stress urinary incontinence (uSUI) were included; along with 40 continent women as a control group. Both groups of women were recruited from the gynecological outpatient clinic. Women of the first group were diagnosed to have uSUI when they had a sociallyunacceptable complaint of involuntary leakage of urine on stress (cough, sneezing or certain movements) and had a urodynamic study showing a stable detrusor pressure curve (Pdet) on valsalva or coughing. ${ }^{3}$ Women of the control group were age-and BMI-matched nulliparous urine-continent women with no previous pelvic surgery. Pregnant women, those who had mixed or urge urinary incontinence, those who had recurrent SUI after a previous anti-incontinence procedure, or previous pelvic surgery, and those who had urinary tract anomalies were not included.

All included women in both groups were subjected to TP ultrasonography using Medison, Sonoscape A6 model with both, 3.5-MHz convex probe and $6.5-\mathrm{MHz}$ endovaginal probe. The endovaginal probe was used for its superior spatial resolution providing more detailed imaging when examining the urethra. For all included women, trans-abdominal sonography was performed before TP scanning to exclude pelvic abnormalities as urethral or urinary bladder diverticulum, lateral cystocele and any pelvic masses. The patient lied supine in lithotomy position while the TP ultrasound is performed with the urinary bladder half full. The $3.5-\mathrm{MHz}$ convex probe was placed on the perineum in sagittal direction and images were recorded at rest and while straining. Then the endovaginal $6.5 \mathrm{MHz}$ probe was placed just beyond the introitus for imaging of the region of interest.
The following parameters were measured;

- The proximal pubo-urethral distance was measured at rest and during straining. Measurements greater than $10 \mathrm{~mm}$ are indicative of bladder neck hypermobility. ${ }^{10}$

- The posterior urethro-vesical angle ' $\beta$-angle; (90$120^{\circ}$ )', defined as the angle formed by the urethral axis and a line drawn tangent to the posterior edge of the bladder base near the bladder neck, was measured at rest and during straining. ${ }^{11}$

- The angle of urethral inclination ' $\alpha$-angle; (60$110^{\circ}$ )', also called the urethropelvic angle, formed by the urethral axis and the central line of the symphysis pubis, was measured at rest and during straining. ${ }^{11}$ Urethral mobility is calculated as the angle during a valsalva maneuver minus the angle at rest. $^{12}$

- The thickness of the bladder wall was measured at the dome of the urinary bladder.

- The urethral diameter measurement was performed inside the lumen of the two internal mucous membranes only at rest images. A urethral diameter greater than $6 \mathrm{~mm}$ suggests intrinsic sphincter deficiency (ISD). ${ }^{10}$

- At rest and on straining images to obtain maximum descent, the position of the bladder neck, and the leading edge of a cystocele were determined relative to the infero-posterior margin of the symphysis pubis.

\section{Sample size justification}

Sample size was calculated using Epi Info® version 6.0, setting the power $(\beta)$ at $80 \%$ and the significance level $(\alpha)$ at 0.05 . Data from a previous study showed that the mean posterior urethro-vesical angle was $120^{\circ} \pm 8^{\circ}$ and $100^{\circ} \pm 8^{\circ}$ during valsalva in women with SUI and control women, respectively. ${ }^{13}$ Calculations according to this value produce a minimal sample size of 40 women in each group.

\section{Statistical methods}

Statistical analysis was performed using SPSS for Windows version 15.0. Data were presented as range, mean \pm standard deviation (for numeric metric variables); range and median (for numeric discrete variables); or number (percentage) for categorical variables. Difference between women of the same group was analyzed using the paired student's t-test. Difference between women of two different groups was analyzed using the unpaired student's t-test. Significance level was set at 0.05 .

\section{RESULTS}

The study included 40 females having stress urinary incontinence and another 40 females as their controls. The mean age of cases was $46.1 \pm 8.06$ years, while that of controls was $43.2 \pm 5.39$ years $(\mathrm{p}=0.062)$. Whereas, body 
mass index (BMI) was 22.58 $\pm 5.29 \mathrm{~kg} / \mathrm{m}^{2}$ for cases compared to controls $21.83 \pm 5.47 \mathrm{~kg} / \mathrm{m}^{2}(\mathrm{p}=0.535)$.

The median parity of included 40 women with uSUI was 3 (range: 1 - 5); of them $28(70 \%)$ of them delivered vaginally. All included women of the control group were nulliparous.

On analysing the transperineal ultrasound findings, no statistical significant difference found between cases and controls at rest, but on straining, statistical significant difference was found regarding dynamic posterior urethral angle and dynamic pubo-urethral distance Table 1 .

Table 1: Comparison of transperineal ultrasound findings in the studied groups.

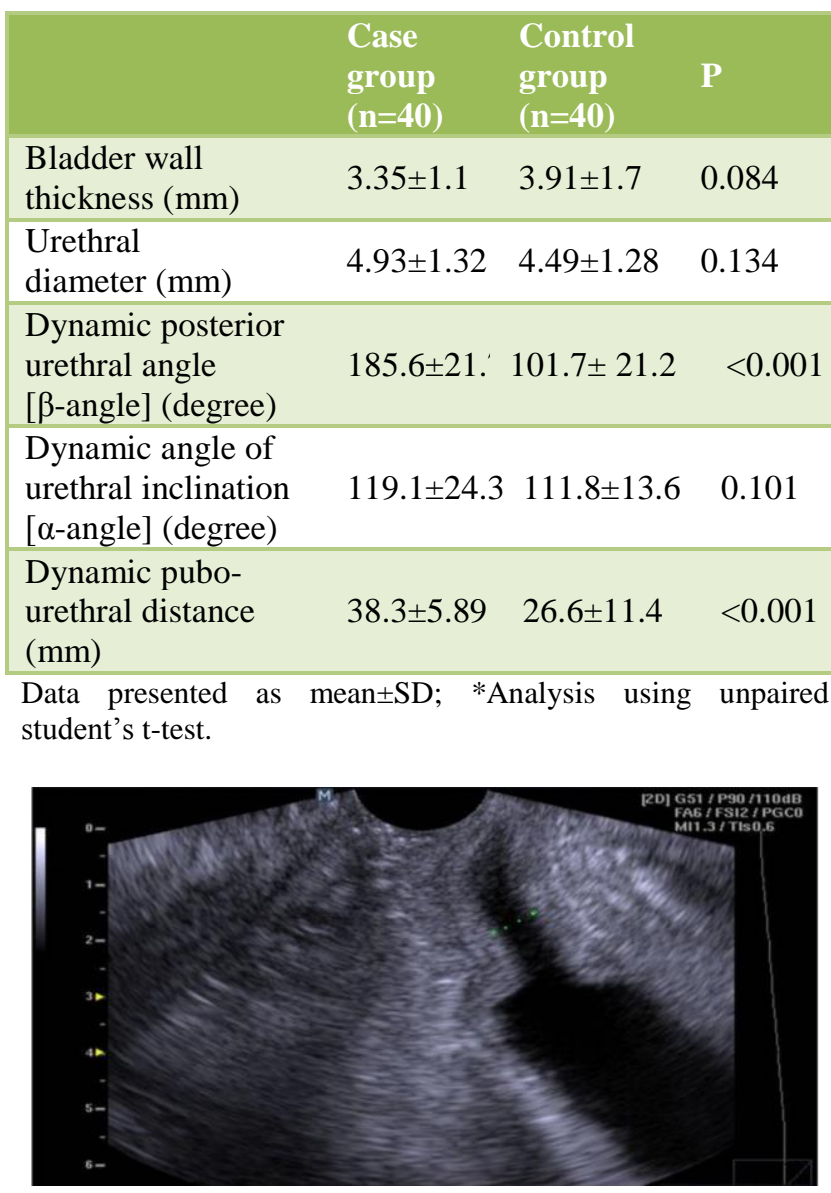

Figure 1: Introital ultrasound measuring urethral diameter $0.76 \mathrm{~cm}$ indicating intrinsic sphincter deficiency.

There was no significant difference in the dynamic angle of urethral inclination between patients with USUI and control group $(\mathrm{p}=0.101)$, yet, the angle of urethral inclination differed significantly in resting and straining phases in SUI patients $(p<0.001)$. There was also significant difference in both the posterior urethral angle $(\mathrm{p}<0.001)$ and the proximal pubo-urethral distance $(\mathrm{p}<0.001)$ during resting and straining phases in patients with uSUI Table 2. No significant difference was found in resting and straining phases for any of the measured parameters in the control cases.

Table 2: Transperineal ultrasound dynamic findings among cases with stress incontinence.

\begin{tabular}{|llll|}
\hline & $\begin{array}{l}\text { On } \\
\text { straining }\end{array}$ & At rest & $\mathrm{P} *$ \\
\hline $\begin{array}{l}\text { Dynamic } \\
\text { posterior urethral } \\
\text { angle [ } \beta \text {-angle] } \\
\text { (degree) }\end{array}$ & $185.6 \pm 21.7$ & $117.4 \pm 18.43$ & $<0.001$ \\
\hline $\begin{array}{l}\text { Dynamic angle of } \\
\text { urethral } \\
\text { inclination [ } \alpha \text { - } \\
\text { angle] (degree) }\end{array}$ & $119.1 \pm 24.3$ & $69.73 \pm 12.1$ & $<0.001$ \\
\hline $\begin{array}{l}\text { Dynamic pubo- } \\
\text { urethral distance } \\
(\mathrm{mm})\end{array}$ & $38.3 \pm 5.89$ & $18.2 \pm 2.29$ & $<0.001$ \\
\hline
\end{tabular}

Data presented as mean $\pm \mathrm{SD} ; *$ Analysis using paired student's ttest.

Of the included 40 cases with uSUI, 27 (67.5\%) had cysto-urethrocele, and $5(12.5 \%)$ had ISD. Urethral diameter was significantly different in patients with ISD $(6.64 \pm 1.23 \mathrm{~mm})$ when compared with patients with uSUI without ISD $(4.83 \pm 1.16 \mathrm{~mm}) \quad(\mathrm{p}=0.03)$. Figure 1 illustrates a case with ISD and Figures 2 and 3 illustrate a case with SUI.

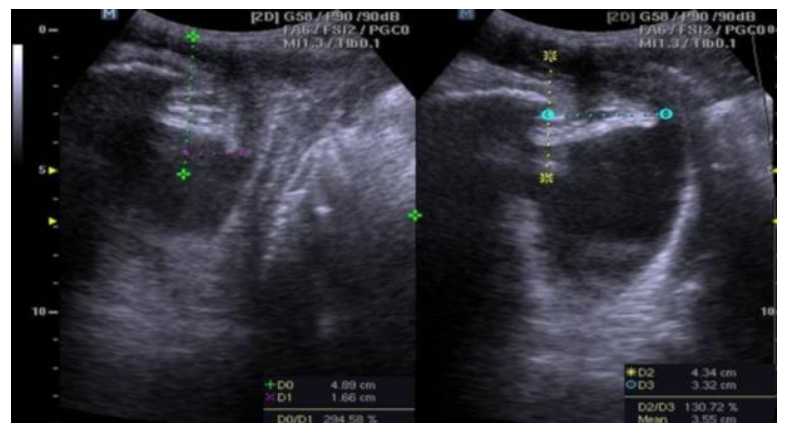

Figure 2: A case with SUI showing increased pubourethral distance on straining indicating bladder hypermobility.

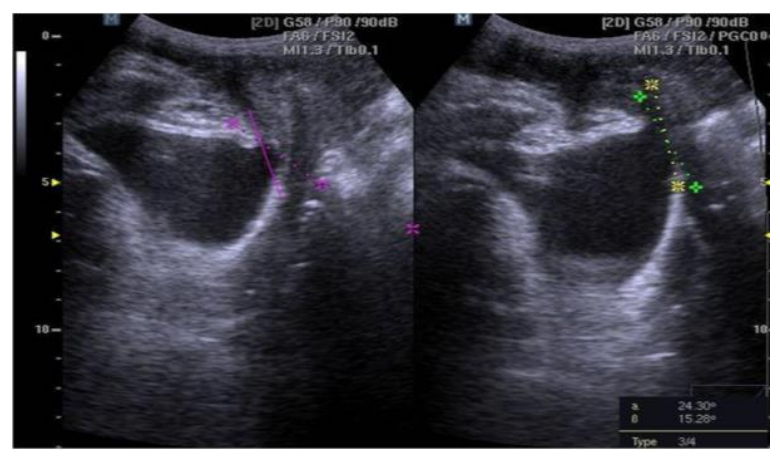

Figure 3: Widening of $\beta$-angle during straining reaching 165 degrees. 


\section{DISCUSSION}

Urinary incontinence is a bothersome condition for many women; with an overall prevalence of approximately $40 \% .^{2}$ Several imaging techniques may be used to supplement physical examination findings in patients with suspected pelvic floor dysfunction.

Bladder neck mobility is essential for the assessment of patients with UI. Modalities used for the assessment of bladder neck mobility as urodynamic study or MRI are considered expensive and might be inconvenient to patients. That is why ultrasonography should be an essential modality in lower urinary tract assessment in patients complaining of UI. ${ }^{10}$ Together with history, clinical examination and urodynamic; it has been shown to improve the accuracy of the diagnosis of the functional and morphological disorder.

The current study was designed to evaluate TP ultrasound findings in females with SUI. The study included 40 females having stress urinary incontinence and another 40 females as their controls. The mean age of cases was $46.1 \pm 8.06$ years, while that of controls was 43.2 \pm 5.39 years. The coordinate system described by Schaer et al was used for its easy repeatability. ${ }^{15}$ Measurements are repeated till adequate strain is maintained. ${ }^{10}$

Vertical component of bladder neck mobility was measured in 297 patients where mobility $>10 \mathrm{~mm}$ was found in $97.1 \%$, whereas mean mobility of $3.2 \mathrm{~mm}$ was measured in control subjects. ${ }^{16}$ Demirci and Fine compared the vertical component of bladder neck mobility in control and SUI subjects and reported it to be similar at rest but differ significantly on stress. Similar results were reported by other studies. ${ }^{4,17,18}$

TP ultrasonography showed significant difference between controls and incontinent women regarding alpha, beta angles and bladder neck descent during valsalva. ${ }^{13}$ Another study found beta angle to be significantly wider in SUI patients, when compared to controls, both at rest and during straining, while, the alpha angle varied significantly only during valsalva. ${ }^{5}$

On analyzing the TP U/S findings in the current study, no statistical significant difference between cases and controls at rest, but on straining, the dynamic pubourethral distance (reflecting bladder neck descent) was significantly different between patients with stress urinary incontinence and the control group $(p=0.04)$.

The dynamic posterior urethral angle (reflecting urethral mobility) was also significantly different between patients with SUI $\left(185.6 \pm 21.7^{\circ}\right)$ and control group $\left(101.7 \pm 21.2^{\circ}\right)(\mathrm{p}<0.001)$.

There was no significant difference in the dynamic angle of urethral inclination between patients with SUI and control group, yet, the angle of urethral inclination differed significantly in resting and straining phases in SUI patients $(p<0.001)$. There was also significant difference in both the posterior urethral angle $(p<0.001)$ and the proximal pubo-urethral distance $(\mathrm{p}<0.001)$ during resting and straining phases in patients with SUI.

Urethral hypermobility results from weakening of urethra supporting structures leading to down-ward displacement and rotation of the urethra. ${ }^{19}$ Intrinsic sphincter deficiency, results from inadequate coaptation and compression due to loss of muscle strength and volume. In intrinsic sphincter deficiency, there is malfunction of the sphincter itself, which leads to an open vesical neck at rest and a low Valsalva leak point pressure. ${ }^{20}$

Both conditions lead to stress urinary incontinence, which results in leakage of urine with increase in intraabdominal pressure when the urethra opens concomitantly, such as during a cough, strain, laugh, or exercise. Most patients have elements of both disorders in varying degrees. ${ }^{19}$

Of the included cases with SUI, $67.5 \%$ were found to have cysto-urethrocele, and $12.5 \%$ were found to have ISD. Urethral diameter was significantly different in patients with ISD $(6.64 \pm 1.23 \mathrm{~mm})$ when compared with patients with SUI without ISD $(4.83 \pm 1.16 \mathrm{~mm})(\mathrm{p}=$ $0.03)$.

Oliveira et al found significantly wider urethral diameters in SUI subjects with ISD than those without or control subjects (6.38 mm, $4.91 \mathrm{~mm}$ and $4.69 \mathrm{~mm}$ respectively). ${ }^{10}$ Ultrasonography agreed with urodynamic study in the diagnosis of $100 \%$ of ISD patients, $66.75 \%$ urethral hyper mobility cases, and $71.5 \%$ of subjects having both conditions. ${ }^{8}$

\section{CONCLUSIONS}

TP ultrasonography seems to be a simple, easy and noninvasive diagnostic tool for the workup of SUI. It showed in this study that the increase in beta and alpha angles (denoting urethral hyper mobility) and the increase of pubo-urethral distance (bladder neck descent) are the main morphological features of SUI.

TP ultrasonography seems to be a good diagnostic option for the evaluation of lower urinary tract morphology, and with the introduction of new modalities of software like 3/4 dimensional ultrasonography together with the increased training availability. The acceptance of TP ultrasonography as a standard diagnostic option for SUI seems to be likely.

Funding: No funding sources Conflict of interest: None declared

Ethical approval: The study was approved by the Institutional Ethics Committee 


\section{REFERENCES}

1. Novara G, Artibani W. Imaging for urinary incontinence: a contemporary perspective. Curr Opin Urol. 2006;16(4):219-23.

2. McNanley AR, Duecy EE, Buchsbaum GM. Symptom-based, clinical, and urodynamic diagnoses of urinary incontinence: how well do they correlate in postmenopausal women? Female Pelvic Med Reconstr Surg. 2010;16(2):97-101.

3. Abrams P, Blaivas JG, Stanton SL, Andersen JT. The standardization of terminology of lower urinary tract function. The International Continence Society Committee on Standardisation of Terminology. Scand J Urol Nephrol Suppl. 1988;114:5-19.

4. Sendag F, Vidinli H, Kazandi M, Itil IM, Askar N, Vidinli B. Role of perineal sonography in the evaluation of patients with stress urinary incontinence. Aust N Z J Obstet Gynaecol. 2003;43(1):54-7.

5. Hajebrahimi S, Azaripour A, Sadeghi-Bazargani H. Clinical and transperineal ultrasound findings in females with stress urinary incontinence versus normal controls. Pak J Biol Sci. 2009;12(21):1434-7.

6. Dietz HP, Steensma AB, Vancaillie TG. Levator function in nulliparous women. Int Urogynecol J Pelvic Floor Dysfunct. 2003;14(1):24-6.

7. Dietz HP. Ultrasound imaging of the pelvic floor. Part I: two-dimensional aspects. Ultrasound Obstet Gynecol. 2004;23(1):80-92.

8. Wahba MH, Abdelsayed RF, Mahmoud AAS. The Functional role of transperineal ultrasound in the evaluation of females with urinary incontinence compared to urodynamic studies. Med J Cairo Univ. 2014;8(2):231-7.

9. Dalpiaz O, Curti P. Role of perineal ultrasound in the evaluation of urinary stress incontinence and pelvic organ prolapse: a systematic review. Neurourol Urodyn. 2006;25(4):301-6.

10. Oliveira FR, Ramos JG, Martins-Costa S. Translabial ultrasonography in the assessment of urethral diameter and intrinsic urethral sphincter deficiency. $\mathbf{J}$ Ultrasound Med. 2006;25(9):1153-8.

11. Minardi D, Piloni V, Amadi A, El AZ, Milanese G, Muzzonigro G. Correlation between urodynamics and perineal ultrasound in female patients with urinary incontinence. Neurourol Urodyn. 2007;26(2):176-82.

12. Costantini S, Esposito F, Nadalini C, Lijoi D, Morano S, Lantieri P. Ultrasound imaging of the female perineum: the effect of vaginal delivery on pelvic floor dynamics. Ultrasound Obstet Gynecol. 2006;27(2):183-7.

13. Pregazzi R, Sartore A, Bortoli P, Grimaldi E, Troiano L, Guaschino S. Perineal ultrasound evaluation of urethral angle and bladder neck mobility in women with stress urinary incontinence. BJOG. 2002;109(7):821-7.

14. Hecht EM, Lee VS, Tanpitukpongse TP, Babb JS, Taouli B, Wong S. MRI of pelvic floor dysfunction: dynamic true fast imaging with steady-state precession versus HASTE. AJR Am J Roentgenol. 2008;191(2):352-8.

15. Schaer GN, Koechli OR, Schuessler B, Haller U. Perineal ultrasound for evaluating the bladder neck in urinary stress incontinence. Obstet Gynecol. 1995;85(2):220-4.

16. Johnson JD, Lamensdorf H, Hollander IN, Thurman AE. Use of transvaginal endosonography in the evaluation of women with stress urinary incontinence. J Urol. 1992;147(2):421-5.

17. Demirci F, Fine PM. Ultrasonography in stress urinary incontinence. Int Urogynecol J Pelvic Floor Dysfunct. 1996;7(3):125-32.

18. Yalcin OT, Hassa H, Ozalp S. Effectiveness of ultrasonographic parameters for documenting the severity of anatomic stress incontinence. Acta Obstet Gynecol Scand. 2000;79(5):421-6.

19. Santiagu SK, Arianayagam M, Wang A, Rashid P. Urinary incontinence-pathophysiology and management outline. Aust Fam Physician. 2008;37(3):106-10.

20. Macura KJ, Genadry RR, Bluemke DA. MR imaging of the female urethra and supporting ligaments in assessment of urinary incontinence: spectrum of abnormalities. Radiographics. 2006;26(4):1135-49.

Cite this article as: Sweed MS, Sharara S.

Transperineal ultrasound evaluation of females with stress urinary incontinence. Int J Reprod Contracept Obstet Gynecol 2016;5:637-41. 